This document was prepared in conjunction with work accomplished under Contract No. DE-AC09-96SR18500 with the U.S. Department of Energy.

This work was prepared under an agreement with and funded by the U.S. Government. Neither the U. S. Government or its employees, nor any of its contractors, subcontractors or their employees, makes any express or implied: 1 . warranty or assumes any legal liability for the accuracy, completeness, or for the use or results of such use of any information, product, or process disclosed; or 2 . representation that such use or results of such use would not infringe privately owned rights; or 3 . endorsement or recommendation of any specifically identified commercial product, process, or service. Any views and opinions of authors expressed in this work do not necessarily state or reflect those of the United States Government, or its contractors, or subcontractors. 


\title{
SCREENING TESTS FOR IMPROVED METHANE CRACKING MATERIALS
}

\author{
J. E. Klein and J. S. Hölder
}

Savannah River National Laboratory: Aiken, SC 29808, james.klein@srnl.doe.gov

Bench scale (1 to 6 gram) methane cracking tests have been performed on a variety of pure elements, some alloys, and SAES ${ }^{\circledR}$ commercial getters St 101, St 198, St 707, St 737, and St 909 to determine methane cracking performance (MCP) of $5 \%$ methane in a helium carrier at $700^{\circ} \mathrm{C}, 101.3 \mathrm{kPa}$ (760 torr) with a $10 \mathrm{sccm}$ feed. The MCP was almost absent from some materials tested while others showed varying degrees of $M C P$. Re, $\mathrm{Cr}, \mathrm{V}, \mathrm{Gd}$, and Mo powders had good MCP, but limited capacities. Nickel supported on kieselguhr (Ni/k), a Zr-Ni alloy, and the $S A E S^{\circledR}$ getters had good MCP in a helium carrier. The MCP of these same materials was suppressed in a hydrogen carrier stream and the MCP of the Zr-based materials was reduced by nitride formation when tested with a nitrogen carrier gas.

\section{INTRODUCTION}

The Savannah River Site (SRS) Tritium Facilities use non-evaporative metal getter beds containing SAES ${ }^{\circledR}$ St 909 to remove oxygen, carbon monoxide, carbon dioxide, and to crack tritiated water, methane, and ammonia contained in various process gas streams. Tritiated methane, and ammonia, impurities will increase facility emissions unless they are processed before release to the environment. Numerous tests have been performed at SRS using St 909 material. ${ }^{1,2,3,4}$

A "consumed" St 909 bed is disposed of as radioactive waste. The cost of St 909 has ranged from $\$ 4000-\$ 4500$ (\$US) and represents a significant cost of a disposable St 909 bed. It is desired to find a less expensive material which has equal or better methane cracking performance (MCP) than St 909.

\section{BACKGROUND}

St 909, a $\mathrm{Zr}\left(\mathrm{Mn}_{0.5} \mathrm{Fe}_{0.5}\right)_{2}$ or $\mathrm{ZrMnFe}$ alloy, was originally developed as a material to dissociate tritiated water and have a low residual tritium concentration in the material lattice. ${ }^{5}$ St 909 has been used in numerous systems and material tests to decompose or "crack" methane, water, and ammonia.
Alloy formation represents an added expense over the cost of the raw materials so elemental materials should be less expensive to use if equivalent MCP can be achieved. Pursuing this logic, the periodic table of elements was reviewed for potential test materials. Elements were eliminated from consideration if they were gases, radioactive (e.g. U, Tc), had some toxic characteristic that would make bed disposal difficult (e.g. Cd, $\mathrm{Pb}$ ), where considered significantly more expensive than other candidate materials (e.g. Au, Pt, Pd, Rh), or where considered extremely air/water sensitive (e.g. Ca, Ba, Eu). The anticipation that operating temperatures near $700^{\circ} \mathrm{C}$ may be needed to achieve desirable kinetics eliminated elements with melting points below $700^{\circ} \mathrm{C}$ (e.g. $\mathrm{Mg}, \mathrm{Zn}$, $\mathrm{Al})$. The remaining elements considered for testing were B, Si, Ti, V, Cr, Mn, Fe, Co, Ni, Cu, Ge, Y, Zr, Nb, Mo, Hf, Ta, W, and Re along with the Lanthanides Nd, Pm, $\mathrm{Sm}, \mathrm{Gd}, \mathrm{Tb}, \mathrm{Dy}, \mathrm{Er}$, and $\mathrm{Yb}$.

During the procurement of materials for testing, some commercially available alloys were also purchased for screening tests and are described below. Also tested were some SAES ${ }^{\circledR}$ commercial getter materials.

The purpose of these cold (non-radioactive) bench scale screening tests was to determine the MCP of the material with a helium carrier gases. Materials considered to have acceptable MCP were also tested with hydrogen and/or nitrogen carrier gases.

\section{EXPERIMENTAL}

The test system has been described previously and used a residual gas analyzer (RGA) and an argon tracer gas with the methane for the tests. ${ }^{1,2}$ A material was activated by flowing $10 \mathrm{sccm}$ helium through the bed at ambient temperature to displace air followed by a 10 sccm flow of helium or hydrogen while the bed temperature was ramped to $700^{\circ} \mathrm{C}$ in approximately 14 minutes. The tests were conducted at $700^{\circ} \mathrm{C}$ at a pressure of $101.3 \mathrm{kPa}$ (760 torr) with a $10 \mathrm{sccm}$ feed of nominal five vol\% methane (4.9 $\mathrm{kPa}$ partial pressure) in a helium, hydrogen, or nitrogen carrier gas for 24 hours. 
Sample size ranged from one to six grams. Ten, six $\mathrm{mm}$ diameter by four $\mathrm{mm}$ tall cylindrical SAES ${ }^{\circledR}$ getter pellets were used for each test. The getters tested, with literature stated nominal alloy atomic composition shown in brackets and weight percent shown in parenthesis, were St 101 [ $\mathrm{Zr}_{61} \mathrm{Al}_{39}$ ] (84\% Zr, 16\% Al), St 198 [ $\left.\mathrm{Zr}_{2} \mathrm{Fe}\right]$ (76.5\% Zr, 23.5\% Fe), St $707\left[\mathrm{Zr}_{57} \mathrm{~V}_{36} \mathrm{Fe}_{7}\right](70 \% \mathrm{Zr}$, $24.6 \% \mathrm{~V}, 5.4 \% \mathrm{Fe})$, St $737\left[\mathrm{Zr}\left(\mathrm{V}_{0.5} \mathrm{Fe}_{0.5}\right)_{2}\right](46.1 \% \mathrm{Zr}$, $25.7 \% \mathrm{~V}, 28.2 \% \mathrm{Fe})$, and St $909\left[\mathrm{Zr}\left(\mathrm{Mn}_{0.5} \mathrm{Fe}_{0.5}\right)_{2}\right.$ or $\mathrm{Zr}-$ $\mathrm{Mn}-\mathrm{Fe}$ ] (40.5\% Zr, 24.5\% Mn, 25.0\% Fe, 10\% Al).

The non-SAES ${ }^{\circledR}$ materials tested are listed in Table I. The majority of the elements and alloys were obtained from the Alfa Aesar ${ }^{\circledR}$ (Ward Hill, MA, USA) Research Chemicals Metals \& Materials catalog. The 60-62 wt\% nickel on kieselguhr (Ni/k) was obtained from Sigma Aldrich. The as-received Ni/k was stabilized with dimethylgloxime whitch was reduced for over 60 hours with hydrogen and produced water, carbon dioxide, and a reduced nickel phase as determined by XRD analysis.

Table I. Elements and Alloy Tested

\begin{tabular}{|l|c|c|c|}
\hline \multicolumn{1}{|c|}{ Material } & $\begin{array}{c}\text { Part } \\
\text { No. }^{{ }^{a}}\end{array}$ & $\begin{array}{c}\text { Wt \% } \\
\text { Purity }\end{array}$ & Size \\
\hline B-Boron & 11337 & 99.9 & -325 mesh \\
\hline Co-Cobalt & 41605 & 99.8 & $-100+325$ mesh \\
\hline Cr-Chromium & 13796 & 99.95 & -200 mesh \\
\hline Cu-Copper & 13990 & 99 & -325 mesh \\
\hline Fe-Iron & 00737 & $99+$ & -200 mesh \\
\hline Gd-Gadolinium & 12896 & 99.9 & -40 mesh \\
\hline Ge-Germanium & 10190 & 99.999 & -100 mesh \\
\hline Hf-Hafnium & 10201 & 99.6 & -325 mesh \\
\hline Mn-Manganese & 36215 & 99.99 & $0.8-3.0$ mm \\
\hline Mo-Molybdenum & 39686 & 99.999 & -325 mesh \\
\hline Nb-Niobium & 10276 & 99.8 & -60 mesh \\
\hline Ni/k & $20878-7$ & - & $-63+75$ mesh \\
\hline Re-Rhenium & 10313 & 99.997 & -325 mesh \\
\hline Si-Silicon & 36212 & 99.999 & -325 mesh \\
\hline Ta-Tantalum & 10344 & 99.98 & -100 mesh \\
\hline Ti-Titanium & 43102 & 99.5 & -200 mesh \\
\hline V-Vanadium & 12234 & 99.5 & -325 mesh \\
\hline W-Tungsten & 10402 & 99.9 & -100 mesh \\
\hline Zr-Zirconium & 13772 & 99.5 & crystal bar turnings \\
\hline Ni ${ }_{3}$ Al & 40005 & $-{ }^{c}$ & -100 mesh \\
\hline Ni-Cr 80:20 wt\% & 36298 & 99.9 & $\begin{array}{c}3-12 \text { mm } \\
\text { sintered lumps }\end{array}$ \\
\hline NiCu-Fe-Mn ${ }^{\mathrm{d}}$ & 36597 & $99.8 \%$ & $-{ }^{\mathrm{e}}$ \\
\hline Zr-Ni 70:30 wt\% & 88406 & $-{ }^{\mathrm{c}}$ & -325 mesh \\
\hline
\end{tabular}

${ }^{\mathrm{a}}$ Alpha Aesar ${ }^{\circledR}$ except Ni/k (Sigma Aldrich).

${ }^{\mathrm{b}} 60$ (to 62) wt\% nickel on silica (kieselguhr). The material was sieved to obtain the stated size material.

${ }^{\mathrm{c}}$ Unspecified purity.

${ }^{\mathrm{d}} \mathrm{Ni}: \mathrm{Cu}: F e: M n: 63$ min.: 28-34: 2.5 max.: 2.0 max. wt\%.

${ }^{\text {e}}$ Plasma spray grade powder, unspecified size.

\section{RESULTS}

Test results, methane outlet partial pressure versus methane cracked (standard cc methane per gram material), are shown in Figures 1, 2, and 3 using a helium carrier gas. Figure 1 shows the $\mathrm{Cu}, \mathrm{Fe}, \mathrm{W}$, and Ta tested decomposed little methane in 24 hours while the B, Mo, $\mathrm{Zr}$, Mn, and Si had limited MCP.

Figure 2 shows the MCP of the remaining elements varied. Some started with a low methane outlet pressure which rose as the amount of methane cracked increased (Nb, Hf, Re, Cr, V, Mo). Others had a methane outlet pressure that increased, decreased, and then increased again (Gd, Ti). Co differed in that after a short increase, the methane outlet pressure decreased as the test proceeded. The Ni/k results were plotted per mass of nickel, assuming $60 \mathrm{wt} \%$ nickel, and produced an almost constant methane outlet pressure after an initial carbon loading of 10 scc per gram $\mathrm{Ni}$.

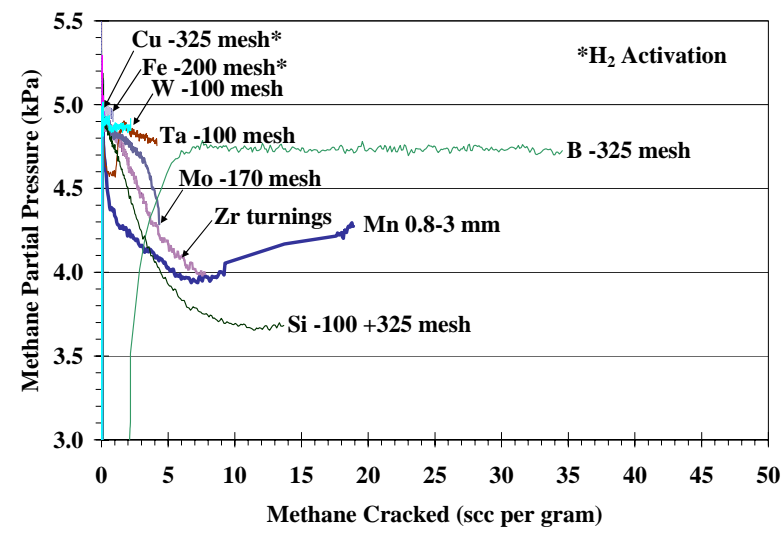

Figure 1: Low MCP Elements with Helium Carrier.

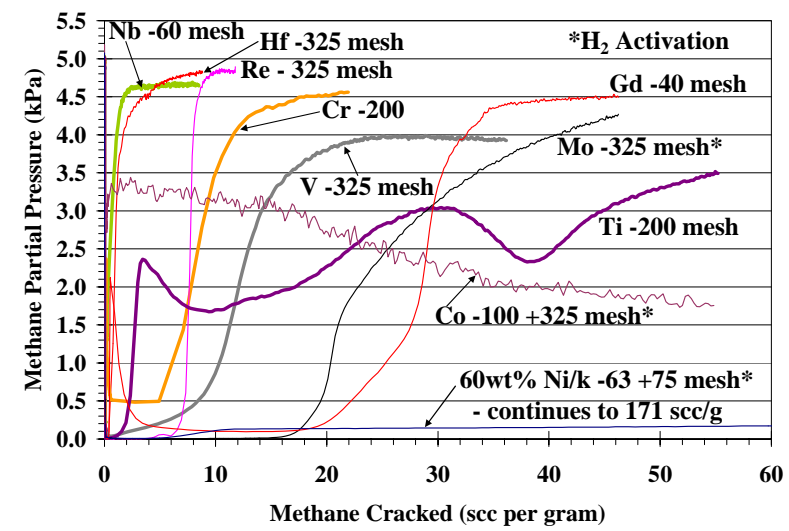

Figure 2: High MCP Elements with Helium Carrier. 
Figure 3 shows the MCP results for the alloys in Table I and the SAES ${ }^{\circledR}$ getters: the $\mathrm{Ni} / \mathrm{k}$ results from Figure 2 were also included. Figure 3 shows the $\mathrm{Zr}$-based SAES ${ }^{\circledR}$ getters had high MCPs, but the Ni-based alloys had varying MCPs. The Zr-Ni alloy had an impressive MCP: the RGA methane signal was reduced by over three orders-of-magnitude for the first 22 hours of the test.

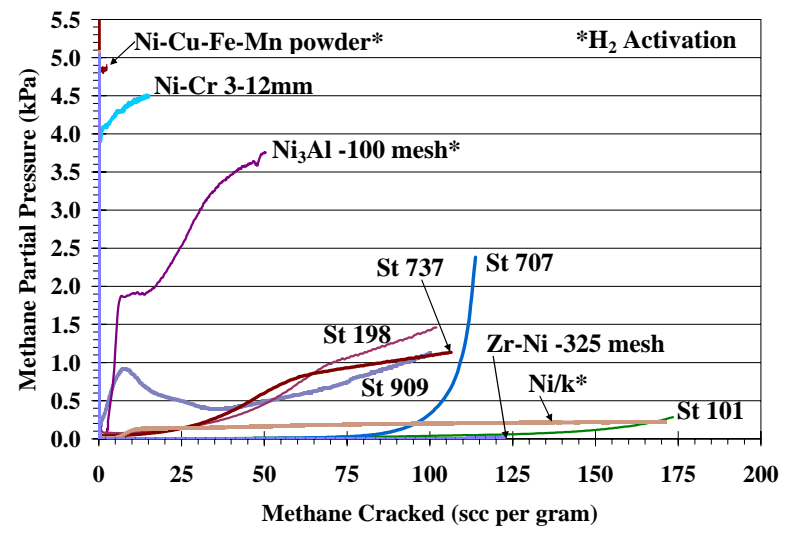

Figure 3: Alloy MCP with Helium Carrier.

Figure 4 and Figure 5 show the MCP results using a hydrogen carrier gas and a nitrogen carrier gas, respectively. Figure 4 shows the hydrogen carrier reduced the MCP of all materials to varying degrees compared to the use of a helium carrier. Figure 5 shows the MCP for $\mathrm{Re}$ and $\mathrm{Ni} / \mathrm{k}$ in nitrogen is similar to that in helium, but the MCP for $\mathrm{Cr}$ and the Zr-based materials was greatly reduced: the MCP was also reduced for $\mathrm{Ni}_{3} \mathrm{Al}$.

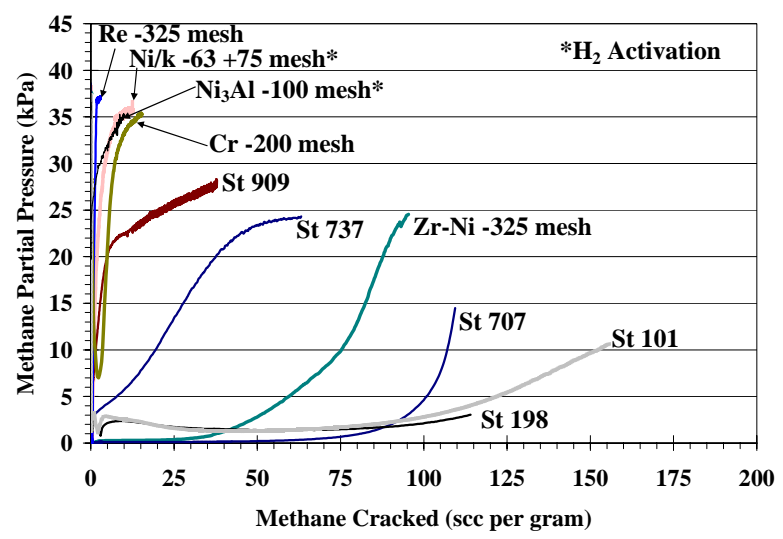

Figure 4: MCP with Hydrogen Carrier.

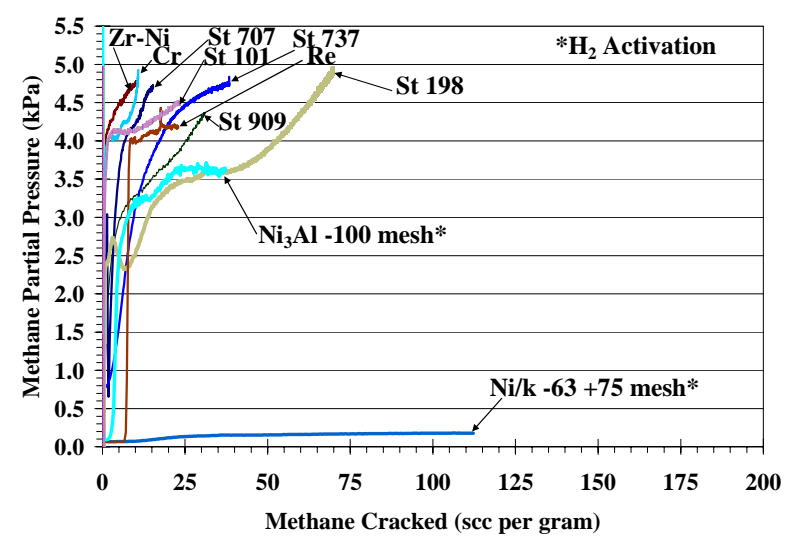

Figure 5: MCP with Nitrogen Carrier.

\section{DISCUSSIONS}

Carbon produced by methane decomposition can remain on the surface of a material or be gettered (i.e. removed from the surface into the material bulk). For the feed gas composition at the test conditions, gas phase equilibria for the methane decomposition reaction are 0.10 vol\% methane, 8.96 vol\% hydrogen, and 90.93 vol\% inert gas: a methane partial pressure of $10.1 \mathrm{kPa}$ (0.76 torr). Materials that reduced methane partial pressures below this (nominal) value were interpreted as gettering the carbon. Materials with methane partial pressures greater than equilibrium values may also be gettering some carbon, but may have insufficient methane cracking kinetics or gettering rates to reduce the methane below its gas-phase equilibrium value.

The $\mathrm{Cu}, \mathrm{Fe}, \mathrm{W}$, and the NiCuFeMn alloy tested lacked sufficient catalytic activity to reduce methane much below its feed composition even though methane decomposition is thermodynamically favorable. Materials such as Nb, Hf, Re, Cr, V, Mo, and Gd exhibit good MCP in helium for low carbon loadings, some even better than St 909, but have reduced MCP at higher carbon loadings. Material shape and size may have some impact on MCP, but the $\mathrm{Cu}$ tested showed that small particle size and the reduction of oxides with hydrogen before testing did not produce good MCP. The excellent MCP of Ni/k was anticipated and has been seen elsewhere. ${ }^{6}$

Figures 2, 3, 4, and 5 give insight into the mechanism of methane decomposition and gettering by the materials. Tests with a hydrogen carrier thermodynamically will favor methane formation, if carbon is available, and the only way methane decomposition will occur is if carbon is continually removed from the surface of the material. Figure 4 shows methane cracking continues due to the relatively fast carbon gettering by the Zr-based materials 
as compared to the slower or non-gettering of carbon by the other materials.

Figure 5 illustrates the impact of nitrogen on MCP. The MCP of the Zr-based materials was greatly reduced by the formation of nitrides ${ }^{7}$, while the MCP of Ni/k and Re are reduced, but perform in a manner similar to that when tested using a helium carrier. The reduction in MCP due to the formation of $\mathrm{Zr}$-nitrides is further supported by exposing SAES ${ }^{\circledR}$ getters to nitrogen before performing methane cracking tests in helium and is shown in Figure 6. Figure 6 shows the MCP of St 101 in a helium carrier was the least sensitive to nitrogen exposure before the test, but Figure 5 shows continual exposure of St 101 to nitrogen greatly inhibits its MCP.

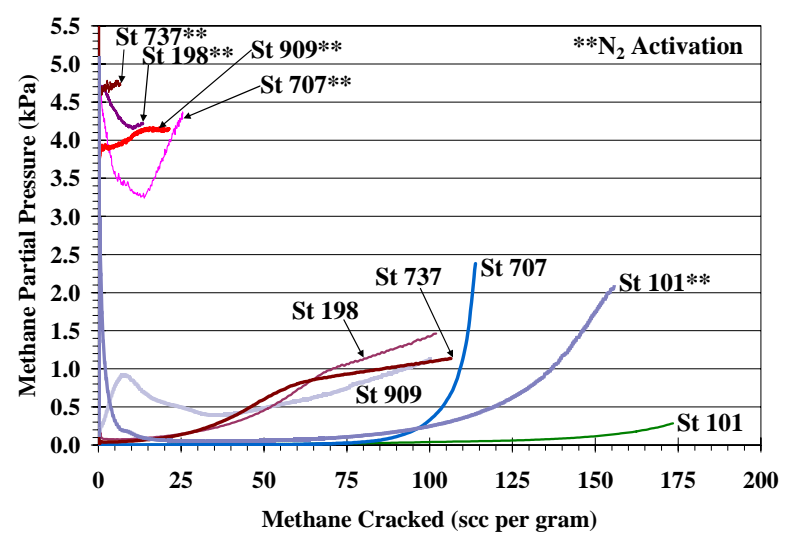

Figure 6: MCP of SAES ${ }^{\circledR}$ Getters with Helium versus Nitrogen Activation.

\section{CONCLUSIONS}

The MCP of was almost non-existent for some materials, even under thermodynamically favorable conditions. Many materials had better MCP than St 909, especially some of the other SAES ${ }^{\circledR}$ getter materials, but no single material was best for use in all three carrier gases. In a helium carrier, the only element to have a better MCP than St 909 was a $60 \mathrm{wt} \%$ silica supported nickel material. The Zr-Ni alloy, St 101, and St 707 had the best MCP, in terms of lowest methane partial pressure, but $\mathrm{Ni} / \mathrm{k}$ and $\mathrm{St} 101$ had the best capacities per gram of material when used in helium.

A hydrogen carrier gas thermodynamically suppressed the methane decomposition reaction and thus the MCP of non-Zr-based materials. $\mathrm{Zr}$ acted as a carbon "sink" for the Zr-based materials which allowed methane decomposition to occur under conditions not favored thermodynamically. The MCP of Ni/k relies on methane decomposition to be thermodynamically favorable and had good MCP in a helium or nitrogen carrier gas. St 909 had the poorest MCP of all the Zr-based materials when tested with a hydrogen carrier gas.

Although Zr acts as a carbon sink for the SAES ${ }^{\circledR}$ getters, the Zr-based materials will nitride and reduce the MCP of the material. St 101 had the smallest impact on MCP in a helium carrier when nitrogen exposure was stopped.

\section{ACKNOWLEDGMENTS}

The authors would like to thank Jody Dye and Joel Jones for there support of this work. This paper was prepared in connection with work done under Contract No. DE-AC09-96SR18500 with the U. S. Department of Energy.

\section{REFERENCES}

J. E. Klein, "SAES St909 Bench Scale Methane Cracking Tests,” Fusion Sci. \& Technol., 41, 998 (2002).

J. E. Klein, "Bench Scale SAES St 909 Tests for Methane and Carbon Dioxide Removal From Helium, Hydrogen, and Nitrogen Streams,” AIChE Spring Meeting, Orlando, FL (2006).

R. H. Hsu and J. S. Holder, "Testing of a Prototype SAES St 909 Getter Bed for Conditioning Gas to a Tritium Stripper System," Fusion Sci. \& Technol., 48, 171 (2005).

[4] J. E. Klein and H. T. Sessions, "SAES St 909 Pilot Scale Methane Cracking Tests,” Fusion Sci. \& Technol., this proceeding (2007).

[5] C. Boffito, A. Conte, and G. Gasparini, "A New Zr-Based Alloy for Tritium Recovery from Tritiated Water,” Trans. Fusion Technol., 27, 69 (1995).

[6] R. Aiello, J. E. Fiscus, H-C zur Loye, and M. D. Amiridis, "Hydrogen Production via the Directe Cracking of Methane Over $\mathrm{Ni} / \mathrm{SiO}_{2}$ : Catalyst Deactivation and Regeneration," Applied Catalysis A: General, 192, 227 (2000).

E. J. Larson, K. J. Cook, J. R. Wermer, and D. G. Tuggle, "Nitriding Reactions with a Zr-Mn-Fe Metal Getter," J. Alloys and Compounds, 330332, 897 (2002). 